\section{THE Rh FACTOR}

BY

\section{ALEXANDER · S. WIENER, M.D., F.A.C.P.}

I was very interested in the review (Journal, Oct. 2,1948, p. 650) of the excellent monograph The $R h$ Blood Groups and their Clinical Effects, by P. L. Mollison, A. E. Mourant, and R. R. Race, as I had just completed reading that publication myself. This fine outline of the present status of the rhesus blood factors is clearly written and gives much useful information. However, it contains a number of errors of omission and commission, and the purpose of this paper is to point them out in view of any further editions that may be planned.

In Chapter I, which deals with the heredity of the $\mathrm{Rh}-\mathrm{Hr}$ blood types, the discussion is unfortunately limited practically exclusively to the linkage theory sponsored by Fisher and Race, while the theory of multiple alleles sponsored by me is hardly mentioned at all. When discussing the linkage theory, moreover, the writers fail to point out that this theory, which is usually ascribed to Fisher, was actually first discussed by me in 1942. I found that the distribution of the $\mathrm{Rh}$ types differed markedly from the equilibrium values to be expected if heredity is determined by distinct pairs of $\mathrm{Rh}-\mathrm{Hr}$ genes, either linked or independent, rather than by a simple series of allelic genes. (These calculations have recently been confirmed and extended by Rife.) Therefore I discarded the theory of linked genes in favour of the theory of multiple alleles. The monograph, too, fails to mention that the theory of multiple alleles is supported by the studies of myself and my collaborators, as well as those of Chown and Race himself, on families comprising more than 2,000 children. The theory is also supported by statistical studies on the distribution of the $R h$ types in the general population, as calculated with the aid of the following formulae (not including the rare genes $r^{y}$ and $R^{z}$ ) published by me in 1944:

$r=\sqrt{\mathrm{rh}}$

$r^{\prime}=\sqrt{\mathrm{rh}^{\prime}+\mathrm{rh}}-\sqrt{\mathrm{rh}}$

$r^{\prime \prime}=\sqrt{\mathrm{rh}^{\prime \prime}+\mathrm{rh}}-\sqrt{\mathrm{rh}}$

$R^{0}=\sqrt{\mathrm{Rh}_{0}+\mathrm{rh}}-\sqrt{\mathrm{rh}}$

$R^{1}=\sqrt{R_{h_{1}}+\mathrm{rh}^{\prime}+R h_{0}+\mathrm{rh}}-\sqrt{R h_{0}+\mathrm{rh}}-\sqrt{\mathrm{rh}^{\prime}+\mathrm{rh}}+\sqrt{\mathrm{rh}}$

$R^{2}=\sqrt{R h_{2}+r h^{\prime \prime}+R h_{0}+r h}-\sqrt{R h_{0}+r h}-\sqrt{r h^{\prime \prime}+r h}+\sqrt{ } r h$

The theory of multiple alleles receives support from the fact that the sum of the gene frequencies calculated with the aid of these formulae closely approximates to $100 \%$

One of the main objections to the linkage theory is its use as a basis for an elaborate and unnecessary duplicate system of nomenclature for the $\mathrm{Rh}-\mathrm{Hr}$ types. Thus the linkage theory sponsored by Fisher and Race, for which there is no substantial evidence, in contrast to the theory of multiple alleles, not only is not original with these workers but has caused them to introduce a cumbersome system of notations which has served only to confuse the subject. For example, the following formulae for "chromosome" frequencies are given by Race in the monograph, being attributed to Fisher as of 1946:

cde $=\sqrt{(\text { 二+- })}$

$\mathrm{Cde}=\sqrt{(-+--)+(++--)+(+\cdots-)}-\sqrt{(-+\square)}$

$\mathrm{cdE}=\sqrt{(-+--)+(-+-+)}-\sqrt{(-+--)}$

These formulae resemble closely formulae (1) to (6) given above, though expressed in less comprehensible hieroglyphics. Another disadvantage of this nomenclature, which Race himself admits on page 10 , is that the C-D-E notations are "somewhat cumbersome to use in speech." The advantages of the simple name "type rh" for triple Rh-negative blood as compared with the designations used by Race-namely, "group - + - " and sometimes "group - - + "-are too patent to require discussion. In Race's notations it is absolutely essential to specify the arrangements of the antisera, since four symbols can be arranged in as many as 24 different ways. Therefore Race has to resort to the use of the "shorthand" symbols $\mathbf{R}_{1}, \mathbf{R}_{2}, \mathbf{r}$, etc., which are merely an adaptation of my original $\mathrm{Rh}-\mathrm{Hr}$ notations. Thus those who insist on using the C-D-E notations are compelled to be familiar with two nomenclatures, while those who use the $\mathrm{Rh}-\mathrm{Hr}$ notations get along very well with one. Moreover, in Table III Race himself finds that the Fisher-Race method of guessing genotypes entails errors as large as $49 \%$, while I have shown that my own notations for the $\mathrm{Rh}-\mathrm{Hr}$ phenotypes and genotypes avoid any error.

The monograph quite properly gives full credit to Levine and his collaborators for their pioneer work in demonstrating the role of iso-immunization to the $\mathrm{Rh}$ factor in the pathogenesis of erythroblastosis. It should have been mentioned, however, that the phenomenon of iso-immunization in pregnancy had been demonstrated previously by Jonsson in 1936 in the case of the $A$ and $B$ factors. Moreover, the concept of isoimmunization in relation to the pathogenesis of erythroblastosis was first advanced by Darrow in 1938, but this worker thought that foetal haemoglobin was the antigen responsible. Levine correctly demonstrated that $\mathbf{R h}$ was the antigen usually at fault, but incorrectly ascribed the effect to $\mathbf{R h}$ agglutinins. Following the independent discovery by myself and Race of the $\mathrm{Rh}$ blocking antibody, I demonstrated that blocking antibodies readily traverse the placental barrier, while agglutinins are effectively held back by the intact placenta, so that the blocking antibodies, or as they are also known the glutinins, are the real culprits in producing the disease, not the agglutinins.

When discussing exchange transfusion the excellent umbilicalcatheter method of Diamond is described in detail, but the saphenous-vein-radial-artery method of Wiener and Wexler is completely ignored even though this was proposed earlier and has been widely used with great success. The umbilical-catheter method has a popular attraction because of its seeming simplicity. However, there have been technical failures with this method even in the hands of experts, who then had to resort to the radial-artery method, which can always be used regardless of the age of the baby. Moreover, while there has been no operative mortality ascribable to the radial-artery technique there have been occasional deaths following the blind umbilicalcatheter method, due not only to air embolism but also to thrombosis and even haemorrhage into the abdominal cavity. In the monograph no mention is made of the fact that, regardless of the method used, one must take care to avoid the possibility of serious shock or even death from hypocalcaemia which may be induced by the relatively rapid introduction of large amounts of citrate, especially when massive exchange transfusions are done. This complication can easily be avoided by repeated careful injection of $10 \%$ calcium gluconate in doses of $1 \mathrm{ml}$. each time $100 \mathrm{ml}$. of blood is administered to the infant.

In the section dealing with the difference between properties of behaviour of univalent and of bivalent antibodies it is rathe surprising to find no mention made of my concepts of agglutination and conglutination. Moreover, there is no reference to my work proving that univalent antibodies pass through the placenta easily while bivalent antibodies do not-an observation of considerable importance not only for the pathogenesis of erythroblastosis but also for immunology in general. The term "albumin agglutinin" does not seem satisfactory, because it is based on a purely artificial though ingenious in vitro test with no counterpart in vivo. If the term "albumin agglutinin" is to be considered acceptable then why not " acacia agglutinin" or "plasma agglutinin" or "anti-human globulin agglutinin"? The terms "glutinin" and "univalent antibody" are free from such objections. As I have demonstrated, the univalent antibodies, after passing through the placenta, coat the foetal red cells, and clumping occurs only in the presence of a third component, conglutinin, found in normal plasma. Conglutinin has been shown to be a colloidal aggregate of plasma proteins which is related to or identical with $\mathrm{X}$ protein, and is analogous in many respects to complement. As shown by me and confirmed by Witebsky, the plasma of the foetus in utero is deficient in 
conglutinin, which, however, matures rather rapidly after birth, thus accounting for the frequently delayed onset of signs and symptoms of the disease. Indeed, the main purpose of exchange transfusion is to remove the baby's coated red cells before they can clump by intravascular conglutination in order to avoid irreversible organic damage which could result from blockage of the circulation. Mollison's statement on page 34 that icterus gravis is probably due indirectly to the primary damage to the baby's red cells is a partial admission of the correctness of these views, and at least does not subscribe to the theory held by many workers that the antibodies act directly on the tissue cells, which were supposed to possess $R h$ antigen.

With regard to the question of nomenclature it is especially important to review the evidence available at once, because the recent U.S. Government ruling that the C-D-E notations must be included in parentheses after the standard $\mathrm{Rh}-\mathrm{Hr}$ notations when labelling antisera has forcibly brought the newer notations to the attention of technicians who had been perfectly content with the original, simpler notations. If the C-D-E protagonists have any real evidence in support of the linkage theory now is the time to present it if they sincerely believe that they are on the right side.

In this connexion the rather extensively cited single exception to the multiple-allele theory found by Glass is merely an illegitimate child, and, at any rate, observations on a single case can hardly affect conclusions based on the far more extensive studies carried out by me and my collaborators. If bonafide exceptions are ever found to the multiple-allele theory, where the possibility of technical errors and illegitimacy are ruled out, then one must consider the more plausible possibility of mutation rather than invoke the highly improbable concept of crossing over between tightly linked genes; and no doubt there must be still other possibilities of which we are not aware in the present state of scientific knowledge. While, after Levine's discovery of the first $\mathrm{Hr}$ factor, it should have been possible to predict the existence of three $\mathrm{Hr}$ factors on the basis of the theory of multiple allelic genes as well as the theory of linked gene triplets, Fisher deserves great credit for his keen insight, which led him to predict the existence of $\mathrm{hr}^{\prime \prime}$ and $\mathrm{Hr}_{0}$ several years before they were finally found.

In conclusion, the various objections which have been raised by $\mathrm{C}-\mathrm{D}-\mathrm{E}$ workers against the original $\mathrm{Rh}-\mathrm{Hr}$ notations have now all been answered without difficulty. It is now time for the C-D-E protagonists to answer the criticisms of their nomenclature or to abandon their stubborn position for the good of the subject.

\section{ANALGESIA IN CHILDBIRTH PRIVATE MEMBER'S BILL}

Mr. Peter Thorneycroft, M.P., who will introduce into the House of Commons on March 4 a private member's Bill intended to ensure that all midwives are trained in the latest methods of analgesia and are provided with the necessary apparatus for giving it, described the provisions of the Bill at a press conference organized by the National Birthday Trust Fund.

The Bill, which consists of nine clauses, provides that, after three years from its passing, a woman who has not received instruction in accordance with rules framed by the Central Midwives Board in the administration of analgesics to women in childbirth shall not be allowed to practise as a midwife ; further, that a woman who may have received such instruction but has not also received such further instruction as may be prescribed by rules framed from time to time by the Board shall not be allowed to practise.

It is declared to be the duty of every local health authority to secure the provision of means to enable midwives so instructed and employed under the National Health Service Act (Part III, Section 23) to administer analgesics to women who desire them. The local health authority is also to ensure that sufficient approved apparatus, facilities for transport, and supplies of drugs are provided and are at all times available for midwives. Those having control or management of a hospital or maternity home are also required to provide such apparatus and drugs. The right of the midwife to administer analgesics is stated in Clause 5 , which runs:
"Any certified midwife who has received such instruction in the administration of analgesics to women in childbirth as may from time to time be prescribed by rules framed by the Board shall be entitled to administer, in accordance with any rules framed and any method approved from time to time by the Board, an analgesic to any woman who desires it during childbirth."

It was stated at the press conference that present arrangements for giving this relief varied very greatly from one area to another. Ample provision existed in some places, while in others arrangements were almost non-existent. It was felt that the Bill raised no issue of party politics, and was one in which all women would be interested. The National Birthday Trust Fund, which had worked for twenty-one years for the right of the mother to have relief if she desired it, and if there was no medical reason why she should not receive it, was strongly supporting the Bill, and believed that if it was passed into law it would not be long before all women, whether confined in hospital or at home, would be able to ask for and obtain analgesia.

Lady Rhys-Williams stated that a survey made recently by the Trust Fund revealed that analgesia was given to only $52 \%$ of women confined in hospital. Of the 17,000 practising midwives, 7,000 were qualified to give gas-and-air analgesia, and the Bill looked forward to advances in anaesthesia and provided for refresher courses for midwives. Lady Rhys-Williams also said that "trilene" might shortly be approved for use by midwives.

The Bill contains penal clauses whereby midwives giving analgesia without the prescribed instruction will be liable on summary conviction to a penalty not exceeding $\mathrm{f10}$, and to a further penalty of the same amount for each day on which the offence continues after conviction. There are similar penalties for the managers of hospitals or nursing-homes who fail to make the required provision.

\section{Preparations and Appliances}

\section{A SIMPLE PORTABLE ANAESTHETIC APPARATUS}

Wing Commander R. L. SOPER, senior specialist in anaesthetics, R.A.F., writes: There is a real need for a simple portable apparatus designed primarily for the non-specialist anaesthetist. The one here illustrated operates normally as a gas-andoxygen apparatus, to which ether or other vapours can be added by means of two Thornton vaporizers. If desired, by means of an air-inlet valve it will act as a simple draw-over

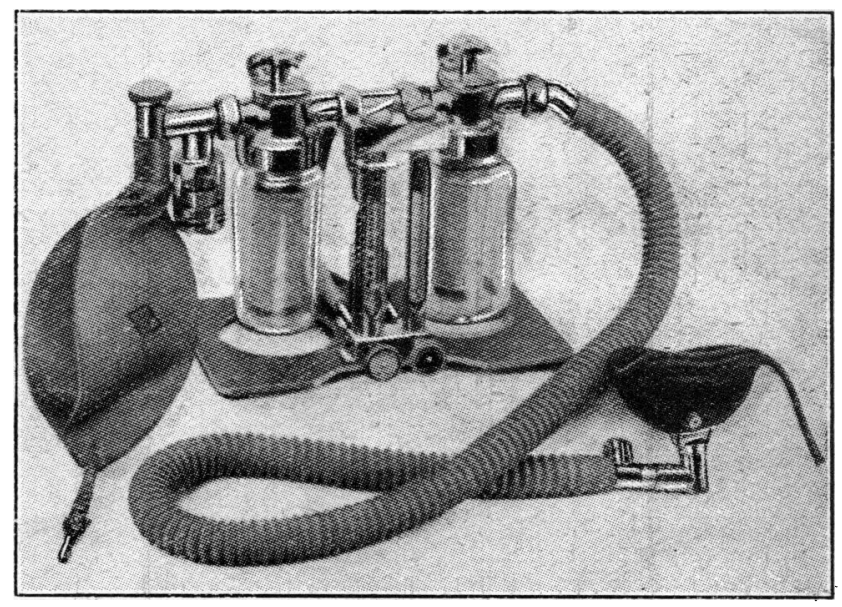

apparatus for trilene-air or ether-air (see the description by Dr. Marrett, Journal, 1942, 1, 643). Rebreathing is readily obtained with either technique. The weight of the complete unit is just over $12 \mathrm{lb}$.

I would like to thank Mr. R. W. Avery for his assistance with the original design, and Mr. E. P. Childerhouse, of Medical and Industrial Equipment, Ltd. (the makers), for help in producing the apparatus. 